\title{
ECOPHYSIOLOGICAL INVESTIGATION ON DROSOPHYLLUM LUSITANICUM: WHY DOESN'T THE PLANT DRY OUT?
}

\author{
Lubomír AdAmec - Institute of Botany - Dukelská 135 - CZ-379 82 Trebon - Czech Republic • \\ adamec@butbn.cas.cz
}

Keywords: physiology: Drosophyllum lusitanicum, roots.

Introduction

Drosophyllum lusitanicum (L.) Link (Portuguese dewy pine; Droseraceae) is the only carnivorous plant with distinctly xerophytic features even during the growing season, in great contrast to the general strategy in other carnivorous plants (Givnish et al. 1984; Juniper et al. 1989). It grows sporadically in a limited area in the subtropical Southern and Western parts of the Iberian Peninsula in Spain and Portugal as well as at the northernmost tip of Africa in Morocco (e.g., Müller \& Deil 2001; Garrido et al. 2003). Drosophyllum is a perennial herb (or short-lived subshrub; Carlquist \& Wilson 1995) with a woody stem base which may be up to $1 \mathrm{~cm}(0.4 \mathrm{in})$ thick and poorly branched. Adult plants may be up to $90 \mathrm{~cm}(35.5 \mathrm{in})$ high. The narrow linear leaves are 15-20 cm (5.9-7.9 in) long and bear numerous immobile emergences (tentacles) with glands and droplets of sticky mucilage (Juniper et al. 1989). The exact morphology of the root is almost unknown; only a relatively thick woody taproot has been described. Guttenberg (1968; see also Adlassnig et al. 2005) presented cross-sections of lateral roots of Drosophyllum and pointed out some peculiarities: the secondary endodermis is heavily suberized, while the rhizodermis is lignified. Carlquist \& Wilson (1995) classified the wood anatomy of Drosophyllum roots as xeromorphic.

Drosophyllum occurs in an area with very hot and seasonally arid conditions, with summer periods of up to three months without rain. Temperatures of the air or the topsoil within plant stands may exceed $40^{\circ} \mathrm{C}\left(104^{\circ} \mathrm{F}\right)$ (Adlassnig et al. 2006). However, during the night, very high air humidity can result in dew. As a facultative heliophyte, Drosophyllum grows preferentially in open habitats without close vegetation, in heathlands and open stands of trees or shrubs (Müller \& Deil 2001). At these sites, the soil is derived from sand or sandstone and is therefore typically rich in large particles (rock or coarse sand), but acidic and poor in organic matter and mineral nutrients (Müller \& Deil 2001; Correia \& Freitas 2002; Garrido et al. 2003; Adlassnig et al. 2006).

In spite of unfavorable climatic and soil conditions, the plants in the field are green, turgescent, and produce trapping mucilage on their leaves even in the middle of the dry season (Adlassnig et al. 2006). However, it is still unclear which principal ecophysiological strategy is used by Drosophyllum to ensure a sufficient water supply and, secondly, which adaptations are used to withstand successfully the very high temperatures in summer. Although a great deal of speculation has been made on ecological peculiarities of Drosophyllum, few specific publications on this subject have been published (Carlquist \& Wilson 1995; Müller \& Deil 2001; Correia \& Freitas 2002; Garrido et al. 2003; Adlassnig et al. 2005, 2006).

Theoretically, there are two possibilities to explain how Drosophyllum maintains its turgescent characters in such conditions: (1) The plant could use a very efficient system of water uptake via deep reaching roots (the natural root system is said to be over $1 \mathrm{~m}$ (40 in) deep!; Hampe, pers. comm.) to cover a relatively great transpiration water loss or (2) the root system is rather inefficient and, thus, shoot transpiration is greatly reduced like in succulents (sensu Lambers et al. 1998). A preliminary observation on Drosophyllum root morphology is ambiguous (Adlassnig et al. 2006). It is evident that the plant absorbs water condensed onto the leaves (probably mainly on hygroscopic drops of mucilage on the tentacle heads) from night fog as dew (e.g., Juniper et al. 1989; Adlassnig et al. 2006). Yet, in the absence of water-storage tissues or organs, such a limited water supply alone cannot provide the plant with a sufficient amount of water for a "normal" transpiration rate during the whole day. Thus, it is possible to hypothesize that transpiration of leaves is greatly reduced by a thick cuticle and low density of stomata. Such adaptations are common among Mediterranean shrubs with evergreen scleromorphic leaves, which grow in similar hot and dry habitats. This feature is associated with a relatively low photosynthetic rate, low stomatal conductivity, and a high osmotic value in leaf cells (Lambers et al. 1998). In this line, a relatively low maximum net photosynthetic rate of only about $6 \mu \mathrm{mol} \mathrm{CO} \mathrm{CO}^{-2} \mathrm{~s}^{-1}$ has recently been found in leaves of outdoor-grown Drosophyllum plants (Hájek \& Adamec, unpublished data), while common values for leaves of herbs lie between about $20-45 \mu \mathrm{mol} \mathrm{CO} \mathrm{m}^{-2} \mathrm{~s}^{-1}(c f$. 
Lambers et al. 1998). However, a low osmotic value of only about $500 \mathrm{mOsmol}$ was found in the field-grown plants (Adlassnig et al. 2006).

The aim of this study was to specify soil $\mathrm{pH}$ at ten sites of Drosophyllum in Spain and Portugal, to document root morphology and root:shoot ratio, and to measure the leaf mineral nutrient content in fieldgrown plants. Thus, the aim is to specify the mechanisms that enable Drosophyllum to withstand hot and arid conditions.

\section{Materials and Methods}

All field investigations at Drosophyllum sites in Southern Spain or Western Portugal were conducted during 26-30 April 2005. At ten Drosophyllum sites, about 15-20 ml of the upper soil layer $(0-1 \mathrm{~cm})$ was sampled from 3-5 representative microsites as a mixed sample within each site and stored in a plastic vial for $\mathrm{pH}$ measurement. The altitude at these sites ranged from about 35 to $680 \mathrm{~m}$ a.s.l. While Drosophyllum is protected by conservation laws in Spain, in Portugal the plant is not protected even though it is less abundant and more endangered. Accordingly, our sampling of plants was done only at two sites in Portugal; the exact locations are not presented here for reason of conservation of the stands. Adult, non-flowering plants were carefully dug out from the soil using a small blade; two plants were dug out from a sandy soil in a man-made Eucalyptus plantation south of Porto and four plants from a sandy-stony soil in a natural shrub-dominated heathland north of Porto. Great attention was placed upon digging out the entire root systems. In spite of these efforts, it is possible that some final parts of fine lateral roots were lost. The total length of the main root was measured as well as the soil depth in which the root tip occurred. The plants were separated into shoots and roots. The root systems were photographed. The roots were washed with tap water, blotted dry, and air-dried in opened plastic bags. The shoots were treated by first removing all dead leaves and captured prey. Then the shoots were dried out using the same protocol as on the roots.

At the site north of Porto, one adult leaf was cut from each of six adult, non-flowering plants for determination of mineral nutrient content. Using a pair of forceps, all captured prey was removed from the leaves, without touching the leaves with fingers. The leaves were put in a clean plastic bag in which they were air-dried.

All samples were fully dried at $80^{\circ} \mathrm{C}\left(176^{\circ} \mathrm{F}\right)$ and the dry weight (DW) was measured in the laboratory. The proportion of root to total DW was estimated. Dry leaves were ground by a pair of forceps and aliquots of 1-3 mg were weighed for mineralization with mineral acids and subsequent $\mathrm{N}, \mathrm{P}, \mathrm{K}, \mathrm{Na}, \mathrm{Ca}$, and $\mathrm{Mg}$ measurement by colorimetry or atomic absorption spectrometry (for all analytical details see Adamec 2000, 2002). Four to five parallel leaf samples were analyzed. Leaf nutrient content is expressed in \% of DW. Water $\mathrm{pH}$ of the collected soils was measured by a pH electrode in soil suspensions (soil:water ca. 1:2 vol./vol., $5 \mathrm{~h}$ ).

\section{Results and Discussion}

At the ten Drosophyllum sites in our study, the soil pH ranged from 3.67 to 5.30 (mean pH 4.46; median $\mathrm{pH} 4.41$; SD 0.41). This $\mathrm{pH}$ range corresponds to the data reported by other authors (Correia \& Freitas 2002; Garrido et al. 2003; Adlassnig et al. 2006) but is rather within the lower range of these literature data. One can conclude from all available data that Drosophyllum prefers acidic soils of a $\mathrm{pH}$ between 4-5, but can also grow in strongly acidic as well as in more or less neutral soils (6.2 \pm 0.5 ; mean $\pm \mathrm{SD}$; Garrido et al. 2003). Thus, the soil $\mathrm{pH}$ range for Drosophyllum growth is rather wide, ca. 3.6-7.0, and confirms some tolerance of neutral soils. In slightly acidic or neutral soils, the bedrock consists of sandy limestone but the soil contains only little water-extractable calcium (Adlassnig et al. 2006). Generally, based upon the available mineral nutrient $(\mathrm{N}, \mathrm{P}, \mathrm{K}, \mathrm{Ca}, \mathrm{Mg}$ ) content, the soils can be characterized as mineral-poor (Correia \& Freitas 2002; Garrido et al. 2003; Adlassnig et al. 2006).

The root system of Drosophyllum was found to be rather well developed, strongly branched, and very fragile (see Figure 1). Presumably, the fragility of the root system is one of the reasons why this species cannot be transplanted when in cultivation unless still in the seedling stage. Yet, the proportion of fine lateral roots, which participate in taking up mineral nutrients and water, might be estimated at only 3-5\% of the total root biomass. The root system has a distinct, heavily lignified taproot which comprises the majority of the biomass. Unexpectedly, the main root was only about $15-37 \mathrm{~cm}(5.9-14.6$ in) long (see Table 1) and reached a depth of only $15-33 \mathrm{~cm}$ (5.9-13 in). The root DW was about $23 \%$ of the total plant DW. These data correspond to those by Adlassnig et al. (2006) who preliminarily found a relatively short root system for Drosophyllum. Although the relatively high proportion of root DW in Drosophyllum falls into the upper range found in carnivorous plants (compared to e.g., Drosera adelae; see Adamec 1997), most other species are wetland plants without woody roots. 
Before the roots were dug out, the stem shoots were cut off at their bases and monitored for at least one hour. No water exudation as a result of root pressure was apparent on the root stumps. Taking into account the xeromorphic anatomical structure of roots (Carlquist \& Wilson 1995; Adlassnig et al. 2005 ex Guttenberg 1968), the root system of Drosophyllum is evidently not able to supply the plant with sufficient water to cover transpiration rates when the weather is hot and the soil is dry. Thus, other adaptation mechanisms should occur on the shoot level.

The mineral nutrient content in Drosophyllum leaves (see Table 2) is comparable to values commonly estimated in leaves of wetland species of terrestrial carnivorous plants (cf. Adamec 1997, 2002; Ellison 2006). On the one hand, Drosophyllum plants growing in nutrient-poor soils were not limited in their growth by shortage of any mineral macronutrient estimated $(\mathrm{N}, \mathrm{P}, \mathrm{K}, \mathrm{Ca}, \mathrm{Mg}$ ). Evidently, the combination of carnivory (mainly $\mathrm{N}, \mathrm{P}$ ) and the root nutrient uptake (mainly $\mathrm{K}, \mathrm{Ca}, \mathrm{Mg}$ ) is sufficient to supply the plants with sufficient mineral nutrients for plant growth (Adamec 1997). On the other hand, leaf K and especially Na content was relatively low and supports the recent finding of relatively low osmotic value in vacuoles of Drosophyllum leaf cells (Adlassnig et al. 2006). These values demonstrate that this species does not behave as a halophyte, as was suggested by Juniper et al. (1989).

Drying of collected shoots and leaves of Drosophyllum in small open plastic bags revealed an important feature of its leaves. The cut-off leaves dried out very slowly for many days. Under the same conditions, sticky leaves of other wetland carnivorous plants (e.g., Drosera, Pinguicula) dry out very quickly, within 1-2 days. Therefore, we can conclude that Drosophyllum leaves are provided with a thick cuticle efficiently preventing water losses by transpiration. Moreover, we expect that the density of stomata on the leaves is low and that the stomata are sunken deeply into the leaf mesophyll. Thus, the adaptation of Drosophyllum to very hot and arid climate could be the same as in other co-occurring xerothermic and xeromorphic evergreen Mediterranean shrubs.

Unlike more conventional shrubs with dry leaf surfaces, Drosophyllum leaves are provided with numerous tentacles producing sticky mucilage that does not dry out in the hot and dry summer. As reported by Darwin (1875, p. 335-336) when a cultured plant was placed in a jar at $100 \%$ air humidity, it produced such a copious amount of constant mucilage secretion that it wetted the plant surface. Thus, it is possible to assume that this mucilage is greatly hygroscopic (unlike most other wetland carnivorous species). During the night, the plants are able to absorb water condensed from oceanic fog as dew onto their mucilage droplets on tentacles. In this way, the mucilage droplets increase their size and water availability (in terms of increased water potential) for the plant overnight and the tentacle heads are able to absorb a part of this condensed water into the leaves. This process of water absorption from the mucilage can stop in the morning, due to

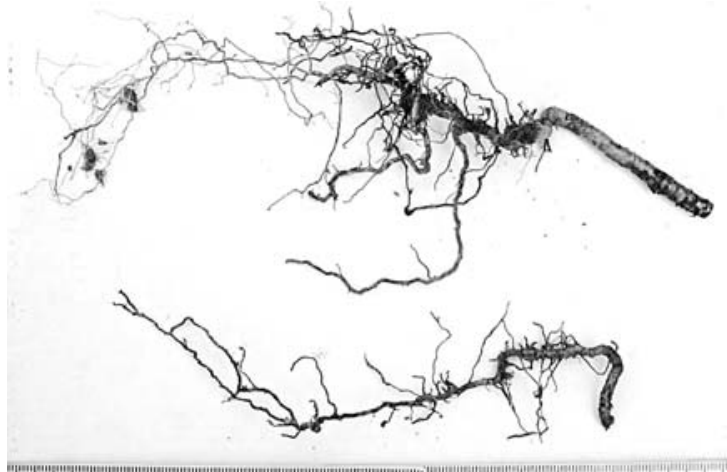

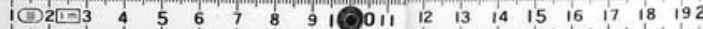

Figure 1: Intact root system of Drosophyllum.

Table 1: Parameters obtained on six plants of $D$. lusitanicum collected at two natural sites near Porto, Portugal, on 29-30 April 2005.

\begin{tabular}{|l|c|c|c|}
\hline & Mean & 1 SE & Range of values \\
\hline Shoot DW $(\mathrm{g})$ & 1.02 & 0.27 & $0.375-1.97$ \\
\hline Root DW $(\mathrm{g})$ & 0.265 & 0.052 & $0.173-0.496$ \\
\hline Root: total biomass $(\%)$ & 23.3 & 3.4 & $14.2-38.0$ \\
\hline Main root length $(\mathrm{cm})$ & 22.2 & 3.9 & $15-37$ \\
\hline Approx. soil depth at the root tip $(\mathrm{cm})$ & 17.6 & 4.0 & $10-33$ \\
\hline
\end{tabular}


Table 2: Mineral nutrient content (in \% of DW) in adult leaves of $D$. lusitanicum collected at natural sites S (2 plants) and N (3 plants) of Porto, Portugal, on 29-30 April 2005. Means \pm 1 SE are shown; $n=4-5$.

\begin{tabular}{|c|c|c|c|c|c|}
\hline $\mathrm{N}$ & $\mathrm{P}$ & $\mathrm{K}$ & $\mathrm{Na}$ & $\mathrm{Ca}$ & $\mathrm{Mg}$ \\
\hline $1.75 \pm 0.14$ & $0.179 \pm 0.032$ & $1.10 \pm 0.09$ & $0.068 \pm 0.022$ & $0.300 \pm 0.040$ & $0.151 \pm 0.017$ \\
\hline
\end{tabular}

increasing air temperature and decreasing relative humidity. Only in the morning, stomata are open, and the rate of photosynthesis can be relatively high. Later, under very hot and dry conditions at noon and afternoon, stomata are already closed and both photosynthetic and transpiration rates are very low ("noon depression of photosynthesis"). Under these conditions, the transpiration stream from the roots is probably zero. As Adlassnig et al. (2006) found a significantly lower temperature on the leaf surface than in the ambient air (by $\left.5.5 \pm 3.8^{\circ} \mathrm{C}\left(42.9 \pm 6.8^{\circ} \mathrm{F}\right)\right)$ during daytime, some minimum transpiration rate is maintained even during hot and dry afternoons. The source of the water for this transpiration can be (1) the mucilage, (2) the water stored in the leaves, and (3) the relatively thick wooden stems.

To confirm this hypothesis, direct field measurement of transpiration rate would be useful. Or at least, a desiccation curve estimated in a laboratory on a cut-off plant shoot could distinguish between transpiration of the mucilage and the leaf. Finally, a determination of cuticle thickness as well as density and anatomy of stomata would demonstrate whether the above hypothesis on the essence of adaptation to hot and dry climate is valid.

Acknowledgements: This study was funded partly by the Research Programme of the Academy of Sciences of the Czech Republic (No. AV0Z60050516). The author is grateful to Drs. Begoña Garrido, Arndt Hampe, and Mr. Mário Valente for guiding through natural sites. Sincere thanks are also due to Ms. Marianne Peroutka, Mr. Wolfram Adlassnig, and Dr. Barry Rice for critically reading the manuscript and valuable comments. No permits were required to access and collect the plant materials as described in this paper.

\section{References}

Adamec, L. 1997. Mineral nutrition of carnivorous plants: A review. Bot. Rev. 63: 273-299.

Adamec, L. 2000. Rootless aquatic plant Aldrovanda vesiculosa: physiological polarity, mineral nutrition, and importance of carnivory. Biol. Plant. 43: 113-119.

Adamec, L. 2002. Leaf absorption of mineral nutrients in carnivorous plants stimulates root nutrient uptake. New Phytol. 155: 89-100.

Adlassnig, W., Peroutka, M., Eder, G., Pois, W., and Lichtscheidl, I.K. 2006. Ecophysiological observations on Drosophyllum lusitanicum. Ecol. Res. 21: 255-262.

Adlassnig, W., Peroutka, M., Lambers, H., and Lichtscheidl, I.K. 2005. The roots of carnivorous plants. Plant Soil 274: 127-140.

Carlquist, S., and Wilson, E.J. 1995. Wood anatomy of Drosophyllum (Droseraceae): Ecological and phylogenetic considerations. Bull. Torrey Bot. Club 122: 185-189.

Correia, E., and Freitas, H. 2002. Drosophyllum lusitanicum, an endangered West Mediterranean endemic carnivorous plant: threats and its ability to control available resources. Bot. J. Linn. Soc. 140: 383-390.

Darwin, C. 1875. Insectivorous Plants. Murray, London.

Ellison, A.M. 2006. Nutrient limitation and stoichiometry of carnivorous plants. Plant Biol. 8: 740-747.

Garrido, B., Hampe, A., Maranon, T., and Arroyo, J. 2003. Regional differences in land use affect population performance of the threatened insectivorous plant Drosophyllum lusitanicum (Droseraceae). Divers. Distrib. 9: 335-350.

Givnish, T.J., Burkhardt, E.L., Happel, R.E., and Weintraub, J.D. 1984. Carnivory in the bromeliad Brocchinia reducta, with a cost/benefit model for the general restriction of carnivorous plants to sunny, moist, nutrient-poor habitats. Amer. Naturalist 124: 479-497.

Guttenberg, H. von 1968. Der primäre Bau der Angiospermenwurzel. 2nd Edition, Gebrüder Borntraeger, Berlin, Stuttgart.

Juniper, B.E., Robins, R.J., and Joel, D.M. 1989. The Carnivorous Plants. Academic Press, London.

Lambers, H., Chapin F.S.III, and Pons, T.L. 1998. Plant Physiological Ecology. Springer-Verlag, New-York.

Müller, J., and Deil, U. 2001. Ecology and structure of Drosophyllum lusitanicum (L.) Link populations in the south-western of the Iberian Peninsula. Acta Bot. Malacit. 26: 47-68. 